\title{
Perfil profissional dos correspondentes internacionais brasileiros ${ }^{1}$
}

\section{Professional profile of Brazilian foreign correspondents}

\author{
Luciane Fassarella Agnez \\ Professora Doutora de Jornalismo do Centro Universitário IESB. \\ <luagnez@gmail.com>
}

\section{Dione Oliveira Moura}

Professora Doutora do Programa de Pós-graduação em Comunicação da Universidade de Brasília. < dioneoliveiramoura@gmail.com>

\section{RESUMO}

Neste artigo observamos a correspondência internacional, enquanto um posto de trabalho na profissão jornalística, a partir da mitologia criada em torno do seu status e passando pelas transformações decorrentes da introdução de novas tecnologias, da política empresarial e do contexto geopolítico. Chegamos às principais características e ao perfil profissional dos correspondentes brasileiros por meio de questionários aplicados a jornalistas brasileiros que atuam ou atuaram como correspondentes internacionais durante a carreira, com o objetivo de levantar informações sobre o perfil sociodemográfico, as trajetórias individuais e as competências que eles mais valorizam para o exercício da atividade.

Palavras-chave: Jornalismo internacional. Correspondente internacional. Perfil profissional.

\begin{abstract}
In this paper we look at the foreign correspondance, while a workstation in the journalistic profession, from the mythology created around its status and going through transformations resulting from the introduction of new technologies, enterprise policy and geopolitical context. We arrived at the main features and the professional profile of Brazilian foreign correspondents by a survey with Brazilian journalists who work or have worked as foreign correspondents during their career, aiming to gather information about the sociodemographic, individual trajectories and skills they most value to perform the activity.
\end{abstract}

Keywords: International journalism. Foreign correspondent. Professional profile.

\section{Introdução}

O correspondente internacional é o profissional que se estabelece em diversas partes do mundo e mantém abastecida a rede de informações

1 Pesquisa recebeu apoio Capes - Coordenação de Aperfeiçoamento de Pessoal de Nível Superior, por meio de bolsa de doutorado nacional e pelo Programa de Doutorado Sanduíche no Exterior. 
formada pelas agências de notícias. Os meios de comunicação de maior porte, especialmente impressos e televisão, quando desejam uma cobertura internacional de alta qualidade, independente e autêntica, também investem nesta atividade jornalística com profissionais próprios, não dependendo exclusivamente dos conteúdos fornecidos pelas agências. Para Hannerz (2004), o correspondente é um repórter que fica "estacionado" em determinado lugar, enviando notícias para seu veículo de origem. Em complemento, essa atividade profissional também pode ser compreendida como a de um mediador e um tradutor de culturas (Rocha, 2013).

Na maior parte das vezes, o correspondente define as próprias pautas e deve partir de um conhecimento aprofundado da realidade local para conseguir expor os fatos de modo detalhado e interessante para o país de origem (Brasil, 2012). O autor sintetiza o que é e o que faz um correspondente internacional:

O correspondente é um repórter fixado numa cidade estrangeira - muitas vezes a capital de um país -, sendo responsável por uma região, um país ou, às vezes, até um continente inteiro. Ele deve enviar matérias regularmente para a redação da sede de seu veículo. Para isso, ele acompanha toda a imprensa local, mantém contatos frequentes com jornalistas e colegas correspondentes e identifica fontes estratégicas - como entidades, governos, diplomatas, militares e outras que possam fornecer informações importantes (Brasil, 2012, p. 778).

Outra característica é o amplo repertório cultural que deve conhecer referente ao país que cobre, incluindo noções históricas, geopolíticas e até mesmo a fluência no idioma (ou nos idiomas, dependendo da região). O revés é que, apesar de toda essa imersão na cultura e nos hábitos da localidade onde vive, não deve perder o referencial do próprio país e nem mesmo o olhar estrangeiro, capaz de observar os fatos numa perspectiva mais conjuntural e menos interna. Logo, é importante manter certo "frescor no olhar", de quem acaba de chegar a um novo lugar. Em contrapartida, a possibilidade de permanecer por um período mais prolongado permite maior domínio da cultura local, compreensão dos fatos e estabelecimento de contatos importantes (Hannerz, 2004).

Estes são alguns dos aspectos que tornam os correspondentes internacionais um grupo distinto de jornalistas no exercício da profissão (Silva, 2011; Rocha, 2013). Para o mercado jornalístico, trabalhar como correspondente estrangeiro pode ser considerado o ponto alto na carreira, representando um reconhecimento da experiência e realizações como profissional. "Os correspondentes estrangeiros representam os melhores e mais brilhantes da 
profissão nos países de origem"2 (Willnat; Weaver, 2003, citado por Rocha, 2013, p. 5).

Para analisar o percurso profissional dos correspondentes internacionais, Hannerz (2004) adota a noção de "carreira" enquanto um caminho a ser percorrido ao longo da vida, não necessariamente de modo planejado ou previsto, mas sempre de forma ascendente, num equilíbrio entre as intenções e as contingências. $O$ autor afirma ser difícil estabelecer um padrão de como as pessoas se tornam correspondentes, o que as motiva e o que as faz permanecer na profissão. No caso da mídia brasileira, o mesmo se verifica.

A partir de tais definições, o objetivo deste artigo é discutir as principais características e o perfil profissional dos correspondentes brasileiros por meio de um questionário aplicado a jornalistas que atuam ou atuaram como correspondentes internacionais durante a carreira, e que levantou informações sobre o perfil sociodemográfico, as trajetórias individuais e as competências que eles mais valorizam para o exercício da atividade. Os dados aqui apresentados fazem parte da pesquisa que resultou em tese de doutorado (Agnez, 2014) sobre a identidade profissional dos jornalistas brasileiros, tendo como recorte a carreira dos correspondentes internacionais.

Começamos a seguir explanando os procedimentos metodológicos, para posterior apresentação e discussão dos resultados alcançados.

\section{Síntese dos procedimentos metodológicos}

O questionário on-line foi formatado no intuito de levantar informações relativas ao perfil dos correspondentes internacionais brasileiros, tais como: período de atuação; gênero; raça; renda; regiões de origem no Brasil; região de cobertura no exterior; tipo de mídia para o qual trabalharam como correspondentes; dentre outros. O levantamento das informações presentes no questionário on-line que aplicamos na pesquisa é inédito no país até o ano de 2013 - não localizamos na busca bibliográfica nenhum levantamento que apresente estes dados. Desta forma, conhecer tal perfil possibilitou uma visão mais abrangente destes profissionais.

Os questionários foram aplicados pela internet, entre 17 de dezembro de 2013 e 20 de janeiro de 2014. A divulgação foi feita por uma lista de e-mails de jornalistas que atuam como correspondentes internacionais de veículos de todo

2 "Foreign correspondents 'represent the best and brightest of their profession in their native countries"' (Willnat; Weaver, 2003, apud Rocha, 201, p. 5). A versão em português é tradução livre das autoras. 
o Brasil. O mailing dos possíveis participantes da pesquisa foi produzido pela autora da tese, que mapeou os jornalistas brasileiros em atuação no exterior, vinculados à grande mídia nacional, e o reconhecimento de profissionais que foram correspondentes em algum momento durante a carreira.

Ao todo, foram enviadas 92 mensagens eletrônicas (e-mails) convidando os jornalistas a participarem da pesquisa, sendo 54 para correspondentes que concentraram a atuação no século XXI e 38 para outros que exerceram a atividade no século XX. Adotamos o anonimato dos respondentes, para conferir segurança e conforto na hora de prestar as informações. As respostas foram voluntárias e autodeclarativas e, ao final, participaram do levantamento 34 profissionais, representando $37 \%$ de adesão.

Dentre os profissionais que responderam ao questionário, 19 estavam atuando como correspondentes internacionais e 15 não mais. Em relação ao período em que atuaram, 12 assumiram o cargo de correspondente internacional pela primeira vez entre 1970 e 2000, enquanto nove começaram entre 2001 e 2010 e 13 após 2010.

O universo para esta pesquisa era desconhecido: todos os jornalistas brasileiros que atuam ou atuaram como correspondentes internacionais. Em mais de cem anos de história na correspondência internacional no jornalismo brasileiro, é quase impossível precisar o número total de jornalistas que exerceram a função. A falta de um registro ou controle desses profissionais, por parte de associações trabalhistas ou ligadas à imprensa também dificultou esse levantamento mais global. Portanto, realizamos um mapeamento dos correspondentes em atuação, como descrito, e identificamos profissionais veteranos e com possibilidade de estabelecimento de contato, pois a maior parte ainda exerce a profissão.

\section{Dados levantados pelo questionário}

O questionário aplicado foi dividido em seis grupos de respostas, com foco no objetivo de traçar o perfil dos correspondentes internacionais brasileiros. Foram estes:

Dados pessoais: perguntas voltadas para as características básicas dos profissionais, como sexo, nacionalidade, grupo racial, naturalidade de nascimento e onde morava e trabalhava antes de se tornar correspondente.

Formação: nível de escolaridade (graduação e pós-graduação) e domínio de idiomas. 
Desenvolvimento da carreira: questionamos a estes profissionais que idade tinham quando se tornaram correspondentes, quantos anos de profissão tinham quando isso aconteceu, qual o último cargo ocupado antes de assumir a função, se era casado e tinha filhos neste momento, que posto ocupou ou gostaria de ocupar quando deixou (ou deixar) de ser correspondente e, por fim, motivações que o levaram a sair do Brasil (se foi a convite profissional ou por razões pessoais).

Na condição de correspondente: total de tempo que passou no posto de correspondente, em quais países atuou e para quais tipos de mídia produziu conteúdos jornalísticos.

Condições trabalhistas: condição empregatícia enquanto trabalhou no exterior (contratado de empresa nacional ou internacional, stringer ou freelancer ${ }^{3}$ ), rendimento e situação financeira (comparada ao padrão de vida que tinha no Brasil).

Perfil ideal: pedimos aos respondentes que apontassem, em nível de importância, as principais competências que julgam necessárias para que um jornalista ocupe o posto de correspondente internacional.

\section{Resultados}

Entre os correspondentes veteranos convidados a participar da pesquisa, apenas $26,3 \%$ eram mulheres, enquanto que entre os que ainda estavam na função esse percentual subiu para $42,5 \%$. Entre os respondentes, a diferenciação também se confirmou: das 34 respostas, apenas 11 foram de jornalistas mulheres.

No que se refere às nacionalidades, 28 respondentes têm apenas nacionalidade brasileira, enquanto que seis deles possuem dupla nacionalidade: quatro deles também tem nacionalidade européia, um é asiático e um é africano.

Resultado semelhante sobre a nacionalidade dos pais destes profissionais: 29 se declararam filhos de brasileiros e cinco afirmaram que ao menos um dos progenitores são de outra nacionalidade, que não a brasileira. Esse tipo de questionamento inicial teve como propósito identificar se, na própria história de vida desses profissionais, já havia alguma origem internacional, contribuindo, por exemplo, para uma experiência anterior no exterior ou no domínio de outros idiomas.

3 Os stringers são colaboradores fixos do veículo, mas sem um contrato formal de trabalho, que residem na região de cobertura; já os freelancers são profissionais que produzem para qualquer veículo e são remunerados por reportagem publicada. 
Em relação ao grupo racial, dos 34 respondentes, 30 se declararam "brancos", enquanto dois preferiram não responder, um se afirmou "pardo" e um "amarelo". Essse predomínio do grupo "branco" (mais de 88\%) é ainda superior aos $72 \%$ identificados na pesquisa de Mick e Lima (2013) sobre o perfil dos jornalistas brasileiros no geral.

Perguntados sobre a formação profissional, 28 afirmaram ter graduação em jornalismo, cinco em outras áreas e apenas um afirmou não ter nível superior. Entre os 34 respondentes, 15 não cursaram nenhuma pós-graduação, sete são especialistas, nove são mestres e três doutores.

Os jornalistas, enquanto grupo profissional, são reconhecidos por um intenso engajamento com a vida profissional (Travancas, 2011), ou seja, a atividade ocupa grande parte do tempo e exige muita dedicação. São também identificados como "trabalhadores sem hora" (Le Cam, 2006), comprometidos com as intempéries dos acontecimentos, o que torna a rotina imprevisível. Com isso, conciliar a vida profissional com a pessoal pode ser um desafio, especialmente no caso dos correspondentes internacionais, quando a mudança para outro país e as longas rotinas diárias de trabalho (problemas com fuso horário, além de ser o único da equipe na região de cobertura) requer um sacrifício para toda a família, o que sugere que jornalistas solteiros e sem filhos poderiam ter maior facilidade para assumir um posto no exterior (Silva, 2011). Entre os respondentes, pouco mais da metade (19) afirmou ser solteiro no momento em que se tornou correspondente internacional e 23 não tinham filhos nesta ocasião.

A faixa etária é outro fator considerado para analisarmos em qual momento de vida e carreira estes profissionais se tornaram correspondentes estrangeiros: 12 deles afirmaram ter assumido a função antes dos 30 anos de idade; 10 afirmaram ter sido na faixa dos 31 aos 35 anos de idade; nove entre 31 e 40; e três acima dos 40 anos de idade.

Entre os que afirmaram ter assumido a função antes dos 30 anos, dois o fizeram na década de 1970, um nos anos 1980, três nos anos 1990, dois na primeira década dos anos 2000 e quatro após 2010. Os números não permitem qualquer tipo de generalização. Tal fato remete ao encontrado por Hannerz (2004) ao investigar o perfil dos correspondentes norteamericanos: não há um padrão, um critério único que defina como e quando se tornar correspondente internacional. Há uma variedade grande de fatores que contribuem para isso, que vão desde oportunidades no ambiente de trabalho a escolhas e condições de vida pessoais. 
Podemos ainda afirmar que o posto de correspondente internacional foi assumido num estágio intermediário das carreiras. Dos que responderam a pesquisa, 16 declararam ter menos de 10 anos de carreira; outros 10 tinham entre 11 e 15 anos de profissão; e oito mais de 16 anos. O Gráfico 1 mostra a distribuição entre os períodos.

Gráfico 1. Tempo de profissão jornalística ao assumir o posto de correspondente

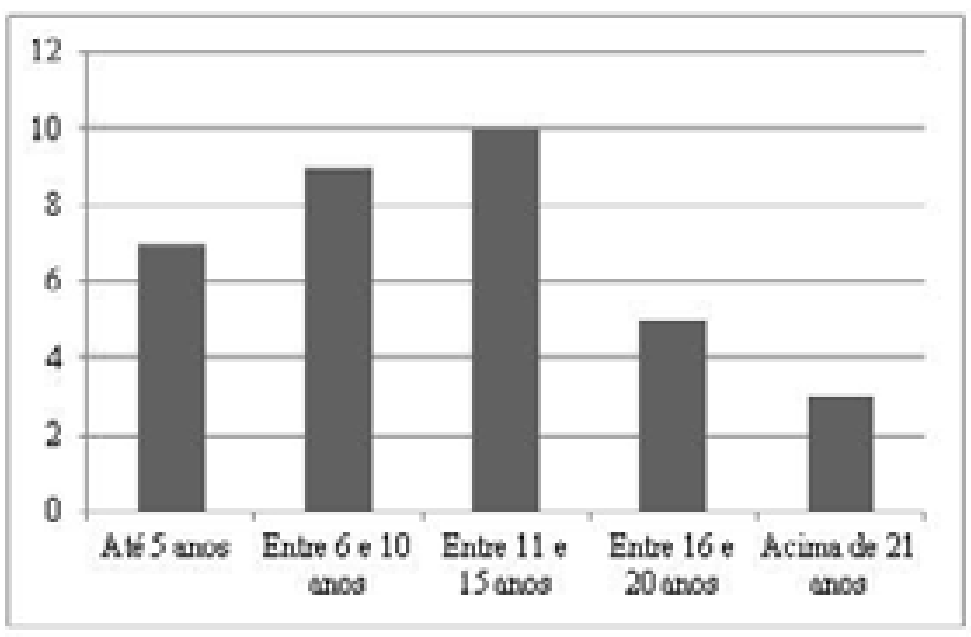

Fonte: elaboração da autora. Questionário on-line respondido por 34 correspondentes internacionais brasileiros no período de 17/12/2013 a 20/01/2014.

Ainda sobre o desenvolvimento das carreiras, do ponto de vista de acúmulo e progressão de postos de trabalho (Hughes, 1960; Pereira, 2012), 13 respondentes exerciam o cargo de repórteres antes de se tornarem correspondentes e seis eram repórteres especiais; seis eram editores e dois eram redatores. Com apenas uma citação cada, apareceram ainda os cargos de editor-chefe, subeditor, pauteiro, secretário de redação, diretor de redação, âncora de rádio e freelancer.

Para os profissionais que não exercem mais a atividade de correspondente, perguntamos qual foi o primeiro posto de trabalho assumido ao fim desse período. Entre os veteranos (15 respondentes no total), seis se tornaram repórteres especiais; dois voltaram como repórteres; quatro assumiram a função de editor ou outro cargo de chefia; dois mudaram de área, ainda dentro da Comunicação; e um se fixou como colunista. Estes dados sinalizam se o posto no exterior pode ser considerado uma "promoção" no sentido da progressão na carreira. Em linhas gerais, metade dos respondentes voltou para exercer 
atividades ligadas à reportagem, enquanto menos de um terço passou para algum cargo de chefia e índice igual se manteve residindo no exterior.

Entre os que ainda exercem a atividade de correspondente (19 respondentes), a expectativa sobre qual atividade assumir depois mostrou que três não desejavam retornar para o Brasil e assim se manter como correspondentes no exterior; cinco gostariam de se tornar repórteres especiais e um de voltar como repórter; quatro tinham o desejo de mudar de área, mas ainda dentro da Comunicação; dois de abrir o próprio negócio; um de se tornar editor ou assumir outro cargo de chefia; um de se tornar colunista ou comentarista; um de se tornar freelancer e trabalhar com independência; e um ainda não sabia.

Dos 34 jornalistas que participaram da pesquisa, 16 exerceram a atividade de correspondente internacional por menos de três anos. Outros sete estiveram no cargo por um período de seis a dez anos e cinco afirmaram ter vidido essa experiência por mais de 20 anos, conforme apresenta o Gráfico 2.

Gráfico 2. Tempo de atuação como correspondente

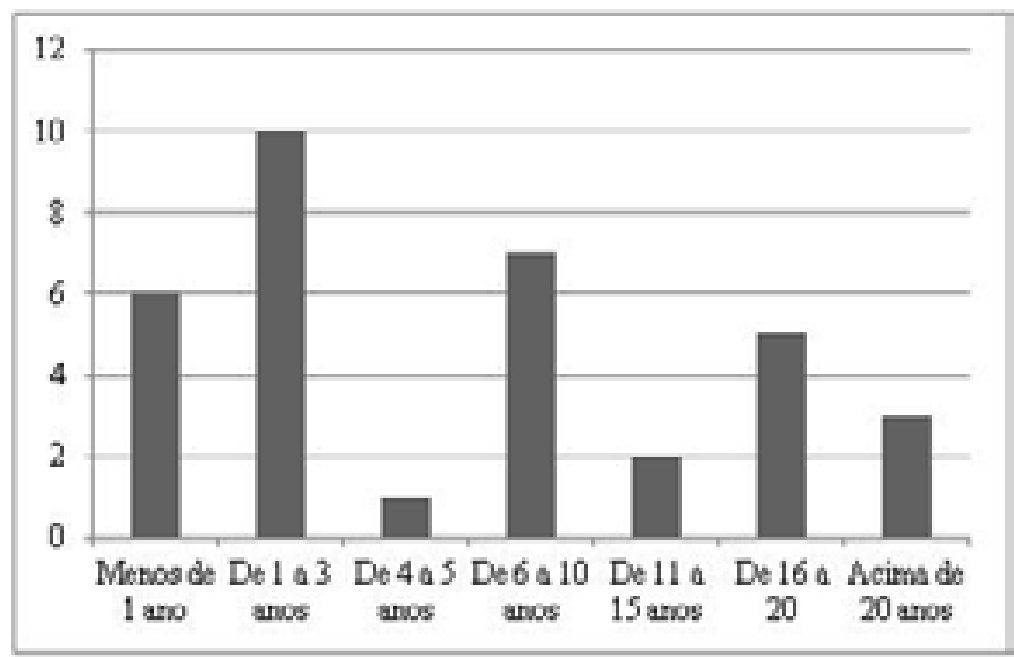

Fonte: elaboração da autora. Questionário on-line respondido por 34 correspondentes internacionais brasileiros no período de 17/12/2013 a 20/01/2014.

O questionário procurou identificar algumas competências profissionais para o exercício da atividade. O domínio de ao menos um segundo idioma é fundamental para um jornalista que pretende se tornar correspondente internacional. Apenas dois respondentes não indicaram o inglês como idioma de uso profissional. O espanhol também é dominado por 29 dos 34 jornalistas. 
O terceiro idioma mais utilizado é o francês (12), seguido pelo italiano (seis), o hebraico (três), o árabe (três) e o alemão (um).

Perguntados sobre o tipo de mídia para o qual produziram enquanto exerceram a função de correspondente internacional, 25 afirmaram ter produzido em algum momento para jornais, 19 para televisão, 18 para internet, 15 para rádio, 11 para revistas e oito para agências de notícias. Vale lembrar que alguns stringers, por exemplo, trabalham para veículos diferentes e as respostas abrangeram todo o período que o profissional esteve no exterior, nem sempre contratado pela mesma empresa. Além disso, jornalistas que pertencem a grupos de comunicação, especialmente no exterior, são demandados a produzir conteúdo noticioso ou opinativo para mídias diferentes da mesma corporação.

Isso também se refletiu na questão sobre o tipo de material que já tiveram que produzir ao longo da atuação no exterior. O texto jornalístico tradicional, informativo, foi resultado do trabalho de 32 respondentes; 19 afirmam já ter produzido algum material em vídeo e 18 em áudio; 15 já foram demandados a escrever artigos opinativos; 13 tiveram que produzir fotografias em algum momento. Sobre a internet, 11 produziram conteúdos para blogs e sete produziram conteúdos para redes sociais.

Os jornalistas também informaram a faixa de renda e as condições trabalhistas ao qual estavam sujeitos durante o exercício da correspondência internacional. O Gráfico 3 apresenta a renda informada, em salários mínimos brasileiros da época em que atuaram. Entretando, sabemos que a variação da economia nacional fez com que o salário mínimo representasse condições de vida mais ou menos elevadas, em determinados períodos da nossa história recente. Também consideramos que os jornalistas veteranos, que atuaram como correspondentes em décadas anteriores, poderiam simplesmente não se lembrar desses valores. Por isso, avaliamos como mais importante entender como eles se sentem ou se sentiam em relação ao padrão de vida no exterior. 
Gráfico 3. Renda (em salários mínimos brasileiros da época em que atuou como correspondente)

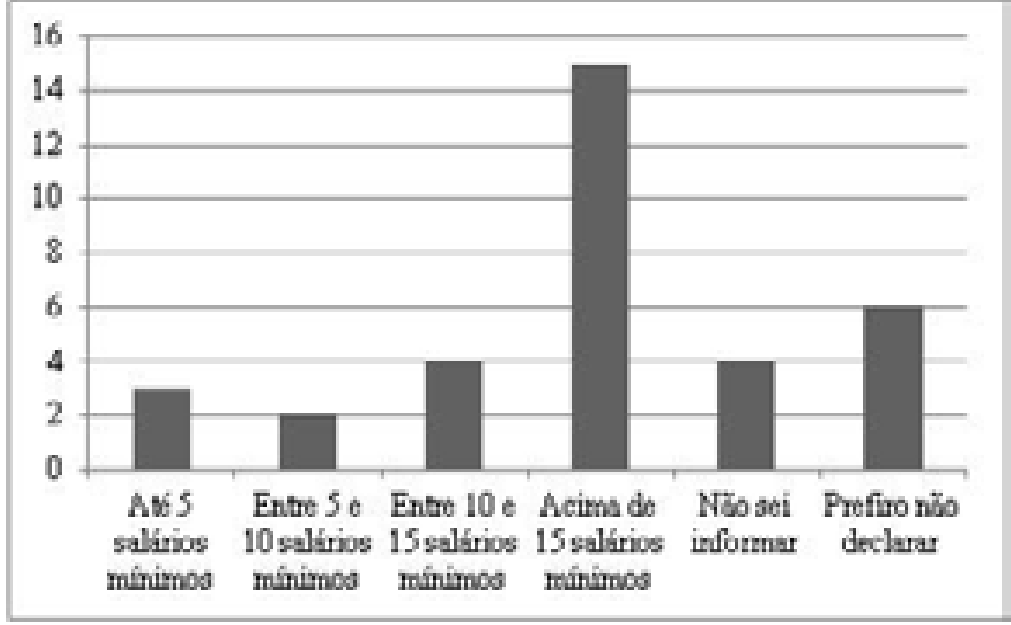

Fonte: elaboração da autora. Questionário on-line respondido por 34 correspondentes internacionais brasileiros no período de 17/12/2013 a 20/01/2014.

Questionados sobre o padrão de vida financeiro, enquanto correspondentes internacionais, 23 afirmaram que a remuneração era satisfatória para se viver em outro país, mantendo as mesmas condições que tinham no Brasil; oito consideravam que o salário no exterior os permitia ter um padrão de vida menor do que tinham no Brasil; e três que esse padrão era elevado, portanto, maior do que no país de origem.

Sobre a condição empregatícia mais frequente no período em que atuaram como correspondentes, 25 se declararam funcionários contratados de empresas de mídia brasileiras, sete eram stringers, apenas um era freelancer e um era contratado por empresa de mídia estrangeira.

Antes de se tornaram correspondentes, 33 já tinham visitado algum país estrangeiro por alguma razão. Destes, sete tinham viajado a lazer e oito tinham feito coberturas fora do Brasil como enviados especiais, enquanto que 18 já tinham morado fora do país, seja por motivos pessoais ou profisisonais.

No momento em que se tornaram correspondentes internacionais, 23 jornalistas afirmaram ter mudado de país a convite de uma empresa de mídia nacional, enquanto quatro foram morar no exterior para fazer um curso de aperfeiçoamento ou pós-graduação e aproveitaram o momento para produzir conteúdos jornalísticos, outros três se mudaram por motivos pessoais ou familiares e apenas um afirmou ter saído com o propósito de se tornar correspondente internacional, ainda que independente. 
Sobre os países nos quais atuaram nas coberturas jornalísticas, enquanto correspondentes, os mais citados foram Estados Unidos e Israel, com nove citações cada. Na sequência aparecem Inglaterra (sete), Portugal (seis), França (cinco), Espanha (cinco), Argentina (quatro), Itália (quatro), Alemaha (três), China (dois), Suíça (dois), Rússia (um) e Japão (um). Outras 18 localidades entre a América Latina, África e o Oriente Médio foram citados por passagens como enviados especiais.

Os próprios correspondentente puderam atribuir cargas de importância às competências que julgam necessárias para um profissional que exerça esta atividade. A Tabela 1 apresenta, em números absolutos, como os próprios correspondentes avaliaram a importância de tais competências.

Tabela 1. Competências para exercer a atividade de correspondente

\begin{tabular}{|c|c|c|c|c|}
\hline Competências & $\begin{array}{c}\text { Muito } \\
\text { importante }\end{array}$ & Importante & $\begin{array}{c}\text { Pouco } \\
\text { importante }\end{array}$ & $\begin{array}{c}\text { Sem } \\
\text { importância }\end{array}$ \\
\hline Falar mais de um idioma & 31 & 3 & - & - \\
\hline $\begin{array}{l}\text { Ser jovem e com o entusiasmo dos } \\
\text { primeiros anos de carreira }\end{array}$ & 4 & 17 & 10 & 3 \\
\hline Ser experiente na profissão & 16 & 12 & 6 & - \\
\hline Ter habilidade com as tecnologias & 15 & 12 & 7 & - \\
\hline Ter um amplo repertório cultural & 20 & 14 & - & - \\
\hline $\begin{array}{l}\text { Ter facilidade de adaptação e inte- } \\
\text { resse por conhecer novas culturas }\end{array}$ & 26 & 8 & - & - \\
\hline Ter facilidade para trabalhar sozinho & 26 & 8 & - & - \\
\hline $\begin{array}{l}\text { Conhecer a fundo a cultura e a } \\
\text { história do país no qual trabalhará }\end{array}$ & 12 & 18 & 4 & - \\
\hline $\begin{array}{l}\text { Ter disponibilidade familiar e pessoal } \\
\text { paramudar de país }\end{array}$ & 26 & 8 & - & - \\
\hline
\end{tabular}

\section{- Fonte: elaboração da autora. Questionário on-line respondido por 34} correspondentes internacionais brasileiros no período de 17/12/2013 a 20/01/2014.

Para finalizar, buscamos identificar de qual região do Brasil os profissionais respondentes eram provenientes. Primeiramente, sobre o estado de nascimento, 13 respondentes são do Rio de Janeiro e nove de São Paulo, outros quatro de Minas Gerais, dois do Rio Grande do Sul e os seguintes estados apresentaram um correspondente: Espírito Santo, Goiás, Amazonas, Pará, Santa Catarina e o Distrito Federal. Mas ao informarem o último estado em que residiram antes de se mudar para o exterior, a concentração foi ainda maior: 16 em São Paulo, 11 no Rio de Janeiro, três no Distrito Federal, dois em Minas Gerais, um em Permanbuco 
e um no Rio Grande do Sul. Esta última resposta já era esperada, considerando a maior concentração de veículos - especialmente os chamados da "grande mídia" - nos principais eixo econômicos do país. Apesar de veículos regionais, como o Correio Braziliense e o Zero Hora, de Porto Alegre, em algum momento já ter trabalhado com jornalistas no exterior, hoje prevalece a cobertura por parte, sobretudo, da imprensa do eixo Rio - São Paulo (Natali, 2004).

\section{Discussão}

A partir de um levantamento demográfico feito por Stephen Hess em 1992, Silva (2011) traçou qual seria o perfil mais comum entre os correspondentes brasileiros, uma vez que não havia nenhum estudo conhecido que faça isso especialmente com jornalistas de nosso país. Alguns traços deste perfil são facilmente reconhecidos: as mulheres eram em geral mais jovens (pois grande parte seria freelancer) e minoria, enquanto os homens seriam mais experientes quando elevados ao cargo de correspondente.

Apesar da feminização que vem ocorrendo no jornalismo brasileiro como um todo (Mick; Lima, 2013), entre os correspondentes ainda é maior o número de homens atuando no cargo. Este cenário se confirmou no presente levantamento, quando apenas 11 dos 34 correspondentes que responderam ao questionário on-line da pesquisa eram mulheres.

Entre os jornalistas, que do ponto de vista social já caracterizam uma fatia da elite em nosso país, os correspondentes seriam a "elite da elite" (Silva, 2011, p. 54), por estudarem em geral em colégios melhores que os demais, pertencerem a famílias de classe média alta, dominarem fluentemente ao menos uma língua estrangeira, além de terem tido a experiência de morar em outro país quando crianças ou jovens. De acordo com o resultado obtido pela pesquisa, em sua maioria os correspondentes que participaram são brasileiros natos, também filhos de brasileiros, brancos e graduados em jornalismo. A maior parte (22 respondentes do questionário on-line) se declara natural dos estados de São Paulo ou Rio de Janeiro, onde também a maior parte trabalhava antes de se tornar correspondente, refletindo a concentração da grande imprensa nesta região.

O idioma mais falado entre os respondentes é o inglês, com quase a totalidade dos jornalistas declarando utilizá-lo em seu trabalho, seguido pelo espanhol e pelo francês. Quase todos já haviam visitado algum país estrangeiro ao menos uma vez antes de se tornarem correspondentes, seja por turismo, questões familiares ou de estudo, e mais da metade (18) já haviam residido em 
outro país. Entretanto, apenas oito já haviam atuado como enviado especial em alguma cobertura jornalística.

A posição de "elite" ou de "topo" da carreira de repórter viria acompanhada ainda de salários mais altos que dos demais colegas, uma autonomia profissional superior e um estilo de vida frequentemente associado a pessoas famosas, autoridades e de relativo prestígio social.

\footnotetext{
É verdade que essa descrição, embora possa ser relativamente fiel à realidade, é ilusória, porque todas essas vantagens são provisórias (se existem, só existem enquanto o beneficiário exerce suas funções) e porque elas não constituem mais do que meras aparências. Mesmo assim, elas são o fulcro do fascínio que a correspondência internacional exerce sobre muitas pessoas e do prestígio que se costuma associar a ela (Silva, 2011, p. 54).
}

Do ponto de vista das condições trabalhistas, 23 jornalistas declararam que se mudaram para o exterior a convite de uma empresa jornalística, quatro para estudar e três por questões familiares. Entre eles, a maior parte (25) atuou como funcionário de empresas jornalísticas brasileiras, sendo que 23 afirmaram que a remuneração recebida era satisfatória para se viver em outro país, enquanto oito disseram que lhes permitia viver num padrão financeiro inferior ao que tinham no Brasil e três que este padrão era mais elevado na condição de correspondente.

O perfil mais tradicional de correspondente, caracterizado como uma espécie de "tipo ideal", apresenta no presente estudo indicativos de mudança: observamos que a figura do correspondente internacional, glorificada entre as décadas de 1970 e 1980 como o topo da carreira de repórter, está ameaçada. O profissional experiente, letrado, imerso a diferentes culturas e capaz de análises conjunturais está dando lugar a jovens correspondentes motivados por boas experiências profissionais, mas submersos em um cenário de precarização da atividade (estrutura e remuneração, por exemplo), como aposta a revisão de literatura e os dados relativos à renda, situação financeira e produção para múltiplas mídias.

Em estudo realizado com correspondentes brasileiros na Europa, Rocha (2013) identificou que a "nova geração" parece estar dominando o campo da correspondência, considerando que os repórteres mais novos estão disponíveis para trabalhar mais horas do que os repórteres seniores e têm um melhor conhecimento sobre as tecnologias. Além disso, esta nova geração de 
correspondentes brasileiros poderia ter mais desenvoltura em termos de línguas estrangeiras do que os colegas antecessores.

Os correspondentes brasileiros também representam o jornalista brasileiro típico: uma pessoa branca e de classe média, altamente educada, satisfeita com a posição profissional e não muito envolvida com os sindicatos de jornalismo (Rocha, 2013). Dos 10 jornalistas brasileiros ouvidos na pesquisa, um tinha apenas a graduação, um pós-graduação, seis eram mestres e dois tinham doutorado.

Em relação à carreira, o estudo ainda identificou que os correspondentes brasileiros não tinham nenhuma formação específica para a área e que o acesso ao cargo foi uma junção de oportunidade, com contatos profissionais anteriores, qualidade do trabalho que desenvolvia no Brasil, mais o domínio de uma língua estrangeira (Rocha, 2013). Como encontramos nos resultados do nosso estudo, esta tendência se confirma, por exemplo, pela faixa etária quando se tornaram correspondentes, indicando estarem entre a fase inicial e intermediária de carreira, além do fato de a mudança ter ocorrido pela oportunidade gerada por uma empresa ou pelo projeto pessoal de viver em outro país.

A trajetória de carreira é ponto importante para analisarmos em qual momento e sob quais condições estes jornalistas assumiram a correspondência internacional. Dos respondentes, 12 chegaram ao posto antes dos 30 anos e dez entre 31 e 35 anos. Portanto, cerca de $65 \%$ deles estavam com menos de 35 anos. Isso representa uma fase intermediária da carreira: 16 respondentes tinham até 10 anos de profissão quando se tornaram correspondentes e outros dez estavam entre 11 e 15 anos.

A maior parte destes profissionais (13 respondentes) eram repórteres ao assumir o posto no exterior. Entre os veteranos, ou seja, aqueles que não exerciam mais a correspondência no momento da pesquisa, oito se tornaram repórteres ou repórteres especiais quando voltaram a trabalhar no Brasil. Já entre os que ainda estavam na posição, novamente a maior concentração de respostas (seis) indicava que eles gostariam de continuar na reportagem na volta ao país de origem.

Sobre as relações familiares, entre os respondentes, 19 afirmaram ser solteiros no momento que se tornaram correspondentes internacionais e 23 não tinham filhos, comprovando a preferência pela maior disponibilidade familiar para mudanças de país e rotinas intensas de trabalho (Silva, 2011). O período médio que 16 que destes profissionais passaram no exterior foi de três anos, outros sete ficaram entre seis e 10 anos e apenas cinco viveram no exterior, trabalhando como jornalistas, por mais de 20 anos. 
Do ponto de vista da cobertura, cada vez menos se exigem textos opinativos do correspondente, eles exercem bem mais a função de repórter, na apuração e relato dos fatos (Natali, 2004). Além disso, alguns autores sugerem uma redefinição do que seria o trabalho de correspondência, por modelos que podem substituir a figura do profissional instalado em outra região (Hamilton; Jenner, 2004).

Estudosinternacionais apontam a redução no número decorrespondentes internacionais, especialmente na imprensa britânica (Moore, 2010; Archetti, 2012) e norteamericana (Hamilton; Jenner, 2004; Lewis, 2010; Williams, 2011). As principais motivações para isto seriam a redução de custos e as facilidades trazidas pelas tecnologias digitais.

Questões financeiras também vêm sendo apontadas como o principal motivo para a redução no número de jornalistas brasileiros no exterior, o que pode ter sido ainda facilitado pelas tecnologias digitais. São poucos os estudos que tratam dessa realidade no Brasil, mas as duas principais obras são editadas por jornalistas que vivenciaram esse período de cortes na prática: um é João Batista Natali (2004), que foi editor de internacional da Folha de S. Paulo; e o segundo é Carlos Eduardo Lins da Silva (2011) que foi por duas vezes correspondente nos Estados Unidos pelo mesmo jornal. Especialmente nestes dois trabalhos, é possível reconhecer que houve uma redução no número de correspondentes internacionais brasileiros a partir da década de 1990, momento de forte crise nas organizações de mídia devido, entre outros motivos, às mudanças de moeda e aos altos investimentos nas tecnologias do cabo e nas novas plataformas tecnológicas, que estavam surgindo naquele momento.

A década de 1990 foi marcada ainda por outras importantes particularidades para o caso brasileiro. A redemocratização e a primeira eleição direta para presidente, seguida pelo impeachment dele, fez com que o noticiário retornasse fortemente para o cenário interno, com a imprensa agora livre da censura. No âmbito internacional, o momento também era de mudança: a queda do Muro de Berlim, em 1989, marcou o fim da Guerra Fria. Nos anos seguintes, eclodiu a Guerra do Golfo e o contexto de tensão se voltou para o Oriente Médio. Do ponto de vista do mercado de mídia, surgiu o fenômeno CNN, fundando o formato de notícias 24 horas ao vivo, de todo o mundo. Somou-se a isso a abertura da internet para o mercado comercial e a entrada dos veículos de comunicação nesta plataforma.

O profissional correspondente tem enfrentado nesse início de século os desafios de se adaptar a um novo cenário tecnológico, comercial (modelos de negócios das empresas de mídia) e até mesmo editorial, com alterações nos 
enfoques das regiões de cobertura na conjuntura internacional. Do ponto de vista tecnológico, Silva (2011) destaca que as tecnologias do final do século XX ajudaram bastante o trabalho do correspondente, que precisou ir se adaptando e adaptando a rotina de produção às novas possibilidades que surgiram. O desenvolvimento das tecnologias acompanhou toda a história dos correspondentes internacionais, das cartas que atravessavam os continentes em navios aos canais de notícias 24 horas e a internet, que permitem ao profissional hoje saber o que está acontecendo em toda parte.

\begin{abstract}
John Maxwell Hamilton reflete em seu livro sobre os correspondentes internacionais: "A tecnologia poupa tempo na transmissão, mas o devora de outras maneiras". A exigência passou a ser por matérias "ao vivo", imediatas. Diminuiu a possibilidade de tempo para pesquisar informações, procurar fontes diversas, confrontar opiniões, pensar. É óbvio que a pressa é inimiga da profundidade. $O$ imediatismo que se exige do jornalista nessa segunda década do século XXI, inclusive do correspondente, pode ser um dos grandes problemas para o futuro de credibilidade (Silva, 2011, p. 66).
\end{abstract}

A introdução das tecnologias digitais está influindo na transformação das rotinas dos jornalistas, de um modo geral, com reflexos diretos na realidade dos correspondentes internacionais. A atividade, que sempre esteve associada ao desenvolvimento das tecnologias da comunicação, tem na internet uma aliada, ao aproximar o profissional da redação, dos colegas de trabalho e das fontes, mas também o desafia ao mantê-lo conectado por longas jornadas, estimulado a produzir conteúdos para múltiplas plataformas.

Até meados dos anos 1990, o correspondente era "os olhos e os ouvidos" do veículo naquela região. Pautava-se muitas vezes pela imprensa do país onde estava e conduzia o trabalho com bastante autonomia. Mas o surgimento dos canais de televisão conhecidos como all news ( 24 horas de notícias no ar) e a expansão da internet comercial na segunda metade da década de 1990 permitiram que as redações dos veículos no Brasil tivessem um maior conhecimento sobre os acontecimentos no mundo, reduzindo a autonomia dos correspondentes (Silva, 2011; Rocha, 2013).

Entre os jornalistas ouvidos por esta pesquisa, dez afirmaram ter trabalhado para apenas um tipo de mídia enquanto estiveram no exterior jornal ou televisão. O surpreendente é que todos estes iniciaram o trabalho como correspondente depois de 1991 e mais da metade já nos anos 2000, período crescente de integração com as mídias digitais. Por outro lado, a maioria 
afirmou ter produzido para múltiplas plataformas, como jornal (25), TV (19), internet (18), rádio (15), revistas (11) e agências (oito).

Outros estudos apontam a questão do trabalho multimídia na rotina do correspondente como uma forte tendência, mas ainda em formatação, não plenamente uma realidade (Moura; Agnez, 2011). O impacto tem sido maior para os profissionais que atuam na mídia impressa (Agnez, 2014).

Para Natali (2004), a principal contribuição trazida pela internet foi o fato de o redator poder sair da posição passiva, ou seja, de só receber material das agências de notícias, para uma posição mais ativa na busca por informações. $\mathrm{Na}$ visão do autor, os informes das agências internacionais são pasteurizados, iguais para todos os veículos: a internet permite hoje colocar a "cereja do bolo", com o redator, mesmo da redação, coletando dados que possa complementar e fazer algum diferencial.

O correspondente internacional tem características próprias na rotina de trabalho, que diferem dos colegas na redação e são fortemente impactadas pelas tecnologias de comunicação. Ele não participa de momentos cruciais da rotina diária de um jornal (seja em qualquer plataforma): pauta e fechamento, por exemplo. Não desfruta do contato diário com colegas, da troca de ideias, e nem do feedback imediato dos superiores. Por conta do fuso-horário, está à frente ou atrás da dinâmica que acontece no país de origem e, por isso, quase sempre trabalha por longas jornadas.

$\mathrm{Na}$ opinião dos próprios correspondentes, diante de critérios apresentados pelo questionário, a habilidade de lidar com tecnologias, 15 respondentes julgam como muito importante, enquanto 12 acham importante e sete pouco importante. Sobre a questão da experiência profissional, uma distribuição parecida se repetiu. O item mais controverso foi o que propôs que os jornalistas deveriam ser jovens e com o entusiasmo característico desta fase da vida profissional, conforme exposto na Tabela 1. Falar mais de um idioma é uma característica indispensável. Associa-se a isso a capacidade de adaptação e interesse por conhecer novas culturas, de trabalhar sozinho e a disponibilidade familiar e pessoal para mudar de país. Repertório cultural e o conhecimento aprofundado do país no qual residirão são apontadas como competências complementares.

\section{Considerações finais}

ParaSilva (2011), a ocupação profissional de correspondenteinternacional, glorificada entre os séculos XIX e XX, passa por uma profunda crise de identidade nesse início de século, assim como toda a atividade jornalística. A questão das 
transformações no modelo de negócio aparece como um problema estrutural básico, impondo uma redução de custos, por um lado, multiplicando a oferta de serviços e, por conseguinte, o trabalho dos jornalistas.

Pode ser um exagero dizer que a correspondência estrangeira está em extinção, mas é evidente que a forma como os correspondentes estrangeiros reúnem, interpretam e transmitem notícias de e sobre lugares distantes vem passando por uma transformação. A tecnologia está conduzindo grande parte desta mudança, e o impacto das novas mídias no jornalismo internacional pode ser visto como benéfico e prejudicial ao mesmo tempo (Williams, 2011). Elas permitem que os repórteres possam ter um acesso facilitado a fontes de notícias e a uma ampla gama de informações, enviar relatos e imagens mais rapidamente e de forma mais eficiente durante a reportagem de campo, bem como fornecer notícias instantâneas do que está acontecendo. No entanto, a nova tecnologia também leva a uma diminuição na capacidade e tempo que os repórteres têm de avaliar a veracidade e a qualidade das informações que recebem, por exemplo.

Este levantamento, a partir das respostas de 34 jornalistas brasileiros que atuam ou já atuaram como correspondentes internacionais em algum momento da carreira, em diálogo com os estudos já desenvolvidos por outros autores, permitiu-nos traçar alguns pontos centrais sobre o perfil destes profissionais, expostos acima.

Por fim, reconhecemos que é clássica uma visão um tanto romântica em relação aos correspondentes internacionais, alimentada pelos próprios profissionais (Williams, 2011). Os correspondentes de guerra, os heróis, aqueles que se arriscam pela informação, embaixadores dos veículos para os quais trabalham, muitas vezes associados à figura do diplomata, o glamour aparente de se viver no exterior, a autonomia, o status mais elevado dentro da carreira de repórter. São muitos os elementos que estimulam o fascínio pela função. Entretanto, como ressalta Williams (2011, p. 94), "a realidade é menos glamorosa e mais mundana. O jornalismo internacional, assim como o restante da profissão do jornalismo, é entediante, repetitivo e frequentemente preso a uma escrivaninha"4. Em outras palavras, o jornalismo internacional está sujeito a uma série de rotinas e práticas, até mesmo burocráticas, que evidenciam que esse glamour está mais presente na visão de colegas, leitores e amigos do que, de fato, na vida profissional destes jornalistas, como comprovam outros estudos de caráter qualitativo e não abordados neste artigo (Agnez, 2014).

4 "The reality is less glamorous and more mundane. International journalism, like the rest of the profession of journalism, is dull, repetitious and often desk bound" (Williams, 2011, p. 94). A versão em português é tradução livre das autoras. 


\section{Referências}

AGNEZ, Luciane F. Identidade profissional no jornalismo brasileiro: a carreira dos correspondentes internacionais. Tese (Doutorado em Comunicação) Programa de Pós-graduação em Comunicação, Universidade de Brasília, julho de 2014.

ARCHETTI, Cristina. Which future for foreign correspondence? Journalism Studies, Vol. 13, No. 5 - 6, pp. $847-856,2012$.

BRASIL, Antônio. A construção da imagem do Brasil no exterior. Revista Famecos. Porto Alegre, v. 19, n. 3, pp. 775-794, set./dez 2012.

HAMILTON, J. M.; JENNER, E. Redifinning foreign correspondence. Journalism, Vol. 5, $N^{\circ} .3$, pp. 301-321, 2004.

HANNERZ, Ulf. Foreign news: Exploring the world of foreign correspondents. Chicago: The University of Chicago, 2004.

HUGHES, Everett C. The Professions in Society. The Canadian Journal of Economics and Political Science,Vol. 26, № 1, pp. 54-61, 1960. Disponível em: http://www. jstor.org/stable/138818. Acesso em: 22 out. 2013.

LE CAM, Florence. L'identité du groupe des journalistes du Québec au défi d'Internet. 2006. Tese (Doutorado em História e Comunicação Pública / Ciência da Informação e da Comunicação). Université Laval / Québec, Universite de Rennes 1 / France.

LEWIS, Dannika. Foreign Correspondents in a Modern World. The past, present and possible future of global journalism. The Elon Journal of Undergraduate Research in Communications, vol. 1, $\mathrm{n}^{\circ}$ 1, 2010.

MICK, Jacques; LIMA, Samuel (org). Perfil do jornalista brasileiro. Florianópolis: Insular, 2013.

MOORE, Martin. Shrinking World: The decline of international reporting in the British press. Media Standards Trust, 2010.

MOURA, Dione O.; AGNEZ, Luciane F. A atuação dos correspondentes internacionais e os impactos da era digital: uma sondagem. In: IX Encontro Nacional de Pesquisadores em Jornalismo, 2011, Rio de Janeiro. Anais do IX Encontro Anual da SBPJor. Rio de Janeiro: ECO - UFRJ, 2011.

NATALI, João Batista. Jornalismo Internacional. São Paulo: Contexto, 2004.

PEREIRA, Fábio. Possibilidade de aplicação do conceito de carreiras profissionais nos estudos sobre jornalismo. In: PEREIRA, Fábio; MOURA, Dione; ADGHIRNI, Zélia. 
Jornalismo e sociedade: Teorias e metodologias. Florianópolis: Insular, pp. 8198, 2012.

ROCHA, Sara de Melo. Brazilian Correspondents in Europe: Careers, Routines, Networks, News Coverage and Role Conceptions. 2013. Dissertação (Mestrado em Jornalismo, Mídia e Globalização). Graduate School of Communication, Universitait van Amsterdam, Amsterdam.

SILVA, Carlos Eduardo Lins da. Correspondente internacional. São Paulo: Contexto, 2011.

TRAVANCAS, Isabel. O mundo dos jornalistas.4.ed. São Paulo: Summus, 2011.

WILLIAMS, Kevin.International journalism. London: Sage, 2011.

Recebido em 15 de fevereiro de 2015.

Aceito em 30 de março de 2015.

Endereço das Autoras:

Luciane Fassarella Agnez <luagnez@gmail.com>

Centro Universitário IESB.

SGAS Quadra 613/614 - Lotes 97 e 98 L2 Sul

Brasília - DF, CEP: 70.200-730.

Dione Oliveira Moura <dioneoliveiramoura@gmail.com>

Universidade de Brasília. Faculdade de Comunicação

Campus Universitário Darcy Ribeiro

Instituto Central de Ciências Norte

Brasília - DF, CEP: 70 910-900 